\title{
Choline kinase inhibition induces exacerbated endoplasmic reticulum stress and triggers apoptosis via CHOP in cancer cells
}

\author{
E Sanchez-Lopez ${ }^{1}$, T Zimmerman ${ }^{2}$, T Gomez del Pulgar ${ }^{3}$, MP Moyer $^{4}$, JC Lacal Sanjuan ${ }^{\star, 3}$ and A Cebrian ${ }^{3}$
}

Endoplasmic reticulum (ER) is a central organelle in eukaryotic cells that regulates protein synthesis and maturation. Perturbation of ER functions leads to ER stress, which has been previously associated with a broad variety of diseases. ER stress is generally regarded as compensatory, but prolonged ER stress has been involved in apoptosis induced by several cytotoxic agents. Choline kinase $\alpha$ (ChoK $\alpha$ ), the first enzyme in the Kennedy pathway, is responsible for the generation of phosphorylcholine (PCho) that ultimately renders phosphatidylcholine. ChoK $\alpha$ overexpression and high PCho levels have been detected in several cancer types. Inhibition of ChoK $\alpha$ has demonstrated antiproliferative and antitumor properties; however, the mechanisms underlying these activities remain poorly understood. Here, we demonstrate that ChoK $\alpha$ inhibitors (ChoKIs), MN58b and RSM932A, induce cell death in cancer cells (T47D, MCF7, MDA-MB231, SW620 and H460), through the prolonged activation of ER stress response. Evidence of ChoKIs-induced ER stress includes enhanced production of glucose-regulated protein, $78 \mathrm{kDa}$ (GRP78), protein disulfide isomerase, IRE1 $\alpha$, CHOP, CCAAT/enhancer-binding protein beta (C/EBP $\beta$ ) and TRB3. Although partial reduction of ChoK $\alpha$ levels by small interfering RNA was not sufficient to increase the production of ER stress proteins, silencing of ChoK $\alpha$ levels also show a decrease in CHOP overproduction induced by ChoKIs, which suggests that ER stress induction is due to a change in ChoK $\alpha$ protein folding after binding to ChoKls. Silencing of CHOP expression leads to a reduction in C/EBP $\beta$, ATF3 and GRP78 protein levels and abrogates apoptosis in tumor cells after treatment with ChoKls, suggesting that CHOP maintains ER stress responses and triggers the pro-apoptotic signal. Consistent with the differential effect of ChoKls in cancer and primary cells previously described, ChoKls only promoted a transient and moderated ER stress response in the non-tumorogenic cells MCF10A. In conclusion, pharmacological inhibition of ChoK $\alpha$ induces cancer cell death through a mechanism that involves the activation of exaggerated and persistent ER stress supported by CHOP overproduction.

Cell Death and Disease (2013) 4, e933; doi:10.1038/cddis.2013.453; published online 28 November 2013

Subject Category: Cancer

Phosphatidylcholine (PC) is a major structural component in eukaryotic membranes and a reservoir of the lipid second messengers diacylglycerol and phosphatidic acid. ${ }^{1}$ Choline kinase alpha $(\mathrm{ChoK} \alpha)$ is the first enzyme of PC biosynthesis. Transformation of cells with the Ras oncogene (found in about $30 \%$ of all human tumors) increases both ChoK $\alpha$ activity and intracellular levels of phosphorylcholine (PCho), ${ }^{2-5}$ as also reported in several human tumors including lung, breast, colon, ovary and prostate. ${ }^{6-10} \mathrm{ChoK} \alpha$ is a critical requirement for breast tumor progression ${ }^{11,12}$ and its overexpression is considered as prognostic factor in lung cancer, ${ }^{13}$ and is associated with increased mortality in hepatocellular carcinoma. ${ }^{14}$ Specific ChoK $\alpha$ inhibitors (ChoKIs) or small interfering RNA (siRNA) inhibition have been proposed as a novel broad-spectrum antitumor strategy with proven antiproliferative activity against oncogene-transformed cells and human cancer cells. ${ }^{15-24}$ MN58b (1,4-[4-4'-Bis-\{[4-(dimethylamine) pyridinium-1-yl] methyl\} diphenyl] butane dibromide) has demonstrated potent antiproliferative and antitumoral activity in vivo. ${ }^{12,16,20-23,25}$ MN58b has been used as a lead molecule for a first generation of compounds, synthesized to improve the tolerability of ChoKIs in vivo. RSM932A (also named TCD$717)^{26}$ has been selected among several molecules as it provided the best results in vitro and in vivo and is in the Phase I clinical trial for the treatment of solid tumors (http:// clinicaltrials.gov/ct2/show/NCT01215864).

We have previously demonstrated that MN58b shows specific cytotoxic effects mediated by an increase of

\footnotetext{
${ }^{1}$ Department of Pharmacology, School of Medicine, UCSD, San Diego, CA, USA; ${ }^{2}$ Centro de Investigaciones Biologicas, CSIC, Madrid, Spain; ${ }^{3}$ Division of Translational Oncology, Health Research Institute and University Hospital Fundación Jiménez-Díaz, Madrid, Spain and ${ }^{4}$ INCELL Corporation, San Antonio, TX, USA

${ }^{*}$ Corresponding author: JC Lacal Sanjuan, Division of Translational Oncology, Health Research Institute and University Hospital Fundación Jiménez-Díaz, Avenida Reyes Catolicos 2, Madrid 28040, Spain. Tel: +34 915504800 ext 3114; Fax: +34 915504800; E-mail: juan.lacal@ fjd.es

Keywords: choline kinase alpha; endoplasmic reticulum stress; CHOP; choline kinase inhibitors; cancer

Abbreviations: ER, endoplasmic reticulum; ChoK $\alpha$, choline kinase alpha; PCho, phosphorylcholine; ChoKls, choline kinase alpha inhibitors; PDI, protein disulfide isomerase; PC, phosphatidylcholine; UPR, unfolded protein response; IRE1, inositol-requiring protein 1; PERK, PKR-like ER kinase; ATF6, activating transcription factor 6; ATF4, activating transcription factor 4; NSCLC, non-small-cell lung cancer; PI, propidium iodide; C/EBP $\beta$, CCAAT/enhancer-binding protein beta; GRP78, glucose-regulated protein, $78 \mathrm{kDa}$; siRNA, small interfering RNA; RB, retinoblastoma protein

Received 03.8.13; revised 06.10.13; accepted 14.10.13; Edited by G Melino
} 
ceramides in hematopoietic cancer cell lines, whereas primary cells suffer a reversible arrest in $\mathrm{G} 1$ being able to recover and proliferate once the drug is removed. ${ }^{23-25}$ However, the precise mechanism by which this selective effect is achieved is not fully understood.

Endoplasmic reticulum (ER) is a central organelle engaged in lipid synthesis, protein folding and maturation. Cellular perturbations, including hypoxia, failure of protein synthesis, folding, transport or degradation, $\mathrm{Ca}^{2+}$ overload and PC depletion can disturb the ER function resulting in ER stress. ${ }^{27-32}$ ER stress-induced apoptosis is becoming increasingly recognized as an important pathogenic factor in a vast number of diseases, including neurodegenerative diseases, diabetes, atherosclerosis and renal disease, and has been recently associated with the mechanism of action of antitumor agents such as vorinostat, sorafenib and bortezomib. ${ }^{33-38}$ ER disturbance triggers several specific signaling pathways, including ER-associated protein degradation and unfolded protein response (UPR). ${ }^{31,39,40}$ The UPR involves the activation of inositol-requiring protein1 (IRE1), PKR-like ER kinase (PERK) and activating transcription factor 6 (ATF6), which selectively suppress protein synthesis, promote the translation of specific proteins and regulate a wide variety of UPR target genes expression, including several ER resident chaperones as glucose-regulated protein $78 \mathrm{kDa}$ (GRP78) and protein disulfide isomerase (PDI) or pro-apoptotic inducers as CHOP (also called GADD153). ${ }^{31,39,40}$

$\mathrm{CHOP}$ is the major pro-apoptotic transcription factor induced by ER stress. ${ }^{39-42}$ Activating transcription factor 4 (ATF4), CCAAT/enhancer-binding protein beta (C/EBP $\beta)$ and CHOP complexes induce the transcription of several target genes that lead to ER stress resolution or apoptosis. One of these genes is TRB3, a novel target of CHOP/ATF4 also involved in CHOP-dependent cell death as a second messenger during ER stress. ${ }^{43}$ Nevertheless, the primary role of UPR is to facilitate the cells to adapt to stress, as revealed by increased sensitivity of ATF4-deficient cells to amino-acid depletion and oxidative stress. ${ }^{44}$ ATF4 activity is critical for maintaining metabolic homeostasis and cell survival under nutrient deprivation. ${ }^{45}$ Thus, ATF4 activates genes that promote restoration of normal ER function and survival, and its elevated expression is associated with resistance to current therapeutic agents including DNA interacting and damaging drugs and proteasome inhibitors. ${ }^{46}$

We report that inhibition of $\mathrm{PC}$ synthesis by interfering with choline kinase activity triggers an exacerbated and persistent ER stress response that promotes cell death in breast, nonsmall-cell lung cancer (NSCLC) and colon-derived tumor cells. We identify CHOP as a key mediator in the cytotoxic effect induced by $\mathrm{ChoK} \alpha$ inhibition. By contrast, non-tumorigenic cells exhibit a transient and attenuated ER stress response that contributes to survival due to overproduction of ATF4. Our results support that $\mathrm{ChoK} \alpha$ inhibition is a bonafide target for developing highly specific novel antitumor cancer drugs.

\section{Results}

ChoKIs arrest cell cycle in non-tumorigenic cells but induce apoptosis in tumor cells. ChoK $\alpha$ inhibition by MN58b has been previously shown to selectively induce cell death in oncogene-transformed NIH3T3 cells and in Jurkat tumor cells, but is cytostatic in non-tumorigenic and primary cells. ${ }^{22,23}$ RSM932A has similar potential antitumor effects in several cell lines being more potent than MN58b in inhibiting ChoK $\alpha$ activity and intracellular PCho levels (data not shown).

Different epithelial mammary cell lines, including the tumorderived cell lines T47D, MDA-MB231 and MCF7, and the immortalized non-tumorigenic mammary cell line MCF10A, were exposed to MN58b or RSM932A at $15 \mu \mathrm{M}$ (around $5 \times I_{50}$ ), for 24 or $48 \mathrm{~h}$. Consistent with the previous published data in primary cells, ChoK $\alpha$ inhibition slowed down MCF10A cell growth suggesting the induction of cell cycle arrest, but reduction in cellular viability was not observed (Figure 1a). In contrast, cellular viability significantly decreased in all tumor cell lines studied (Figure 1a). Cell cycle modulation by ChoKIs was further evaluated by propidium iodide (PI) flow cytometry analysis. ChoKls induced G1 phase cell cycle arrest in MCF10A cells but induced cell death in T47D (Figure 1b), MDA-MB231 and MCF7 tumor cell lines (data not shown). Furthermore, DAPI staining revealed small and bright nuclei and 'apoptotic bodies' in T47D cells (Supplementary Figure 1A), conversely, MCF10A nuclei structure was not modified after treatment.

Normal derived colon mucosa cell line NCM460, ${ }^{47}$ the colorectal cancer cell line SW620 and the lung tumor-derived cell line $\mathrm{H} 460$ were also analyzed to verify that the differential effects observed were not cell type specific. As in mammary cell lines and consistent with previous data, colorectal and lung cancer cells were triggered to apoptosis, whereas normal colon cells were arrested at G0/G1 after ChoK $\alpha$ inhibition with either RSM932A or MN58b (Figure 1c).

A marked reduction in cyclin D1, phosphorylated and total retinoblastoma protein $(\mathrm{RB})$ and $\mathrm{E} 2 \mathrm{~F} 1 \alpha$ was observed in tumor cells (Supplementary Figure 1B), suggesting a defective regulation in the G0/G1 to $S$ phase checkpoint. In nontumorigenic cells, a significant reduction in cyclin D1 and phosphorylated RB (pRB) was also observed; however, $\mathrm{E} 2 \mathrm{~F} 1 \alpha$ and $\mathrm{RB}$ levels were only slightly modified, indicating that G0/G1 arrest was due to the RB-E2F1 $\alpha$ complex (Supplementary Figure 1B). Tumor cells showed pro-caspase 3 and PARP degradation after 24 and $48 \mathrm{~h}$ of treatment, suggesting that these proteins are not the main trigger mechanism for the apoptotic program (Supplementary Figures $1 \mathrm{~B}$ and $\mathrm{C}$ ).

ChoKls induce exaggerated and persistent production of ER stress-related proteins in tumor cells, but promote moderated ER stress response in non-tumorigenic cells. ER stress response is triggered by different cytotoxic agents or intracellular toxic insults. ${ }^{39}$ Increased expression of ER stress-related genes was observed as early as $6 \mathrm{~h}$ after ChoKls treatment, remaining elevated until $48 \mathrm{~h}$, in T47D, MDA-MB231 and MCF7 tumor cell lines (Supplementary Figures 2 and 3). These genes were also upregulated between 9 and $48 \mathrm{~h}$ in non-tumorigenic MCF10A cells (Supplementary Figure 2). However, CHOP and C/EBP $\beta$ expression levels were higher in tumor cells than in the nontumorogenic cells MCF10A (Supplementary Figures 2A and B), whereas ATF4 and TRB3 overexpression was markedly higher in MCF10A (Supplementary Figures 2C and D). 

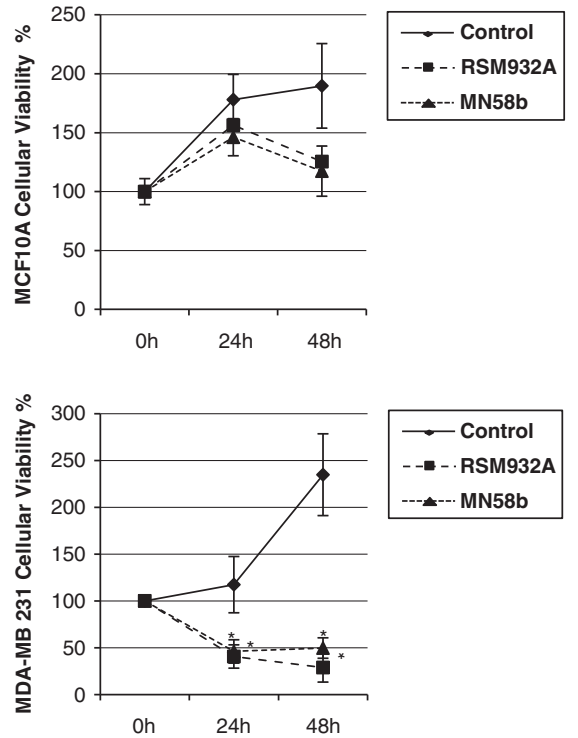

b

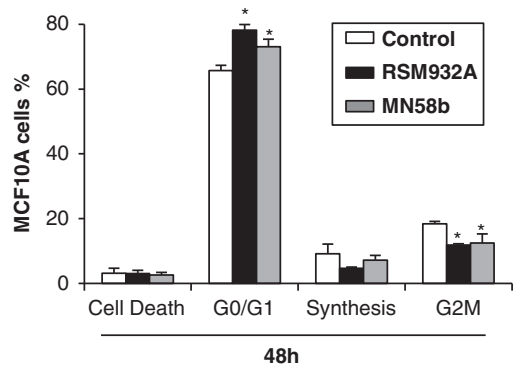

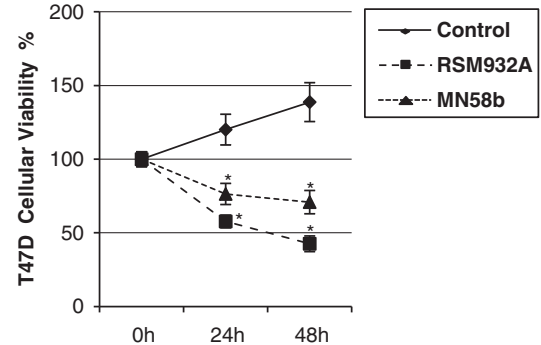
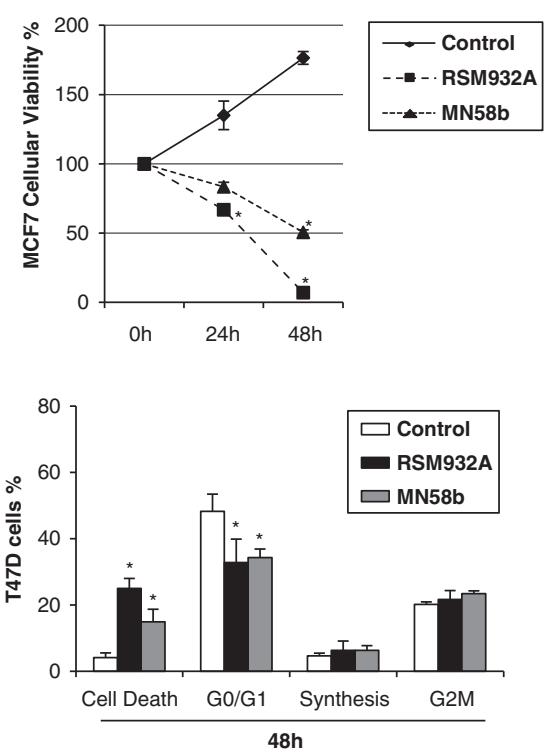
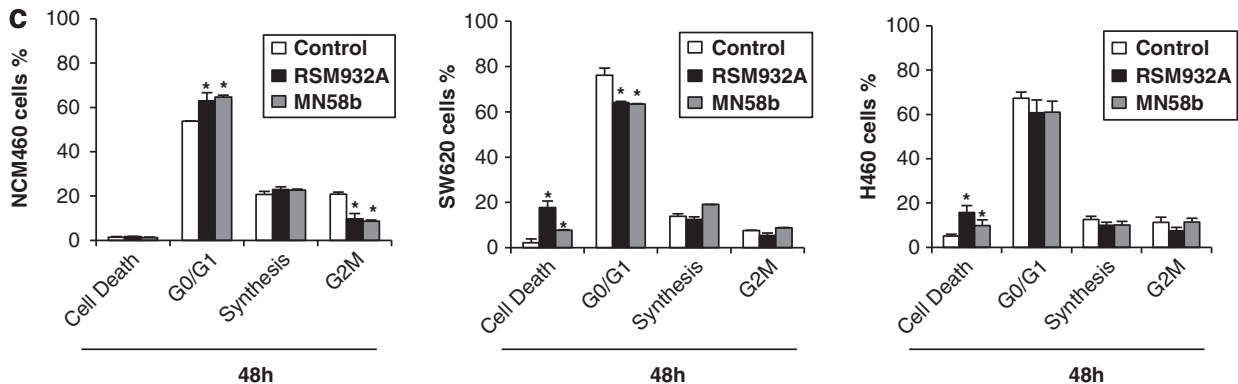

Figure 1 Choline kinase $\alpha$ inhibitors induce cell death in tumor cells and cause cell cycle arrest in non-tumorigenic cells. (a) MTT proliferation assay was performed in MCF10A non-tumorigenic cells, T47D, MCF7, MDA-MB231 breast cancer cell lines. Figures show data as mean \pm S.E.M. of five independent experiments each one performed in quadruplicated. ${ }^{*} P<0.05$ versus control cells after addition of ChoKls. (b) Graph bars show DNA content analysis by PI, and flow cytometry data shown as mean \pm S.E.M. of three independent experiments each one performed by duplicated. ${ }^{*} P<0.05$ versus control cells. (c) Bars show DNA content analysis by flow cytometry data shown as mean \pm S.E.M. of three independent experiments each one performed by duplicated. ${ }^{*} P<0.05$ versus control cells

To further evaluate the effects of ChoK $\alpha$ inhibition on the ER stress signaling pathway, protein levels were analyzed. CHOP protein levels were significantly increased in T47D cells as early as $9 \mathrm{~h}$ compared with non-tumorogenic cells (Figure $2 \mathrm{a}$ ), with a maximum at $24 \mathrm{~h}$, and remained elevated after $48 \mathrm{~h}$. Similar data were observed for C/EBP $\beta$ (Figure 2b), GRP78 (Figure 2c), IRE1 $\alpha$ (Figure 2d) and TRB3 (Figure 2f), and confirmed in MDA-MB231 tumorderived cell line (Figure 2g). In T47D tumor cells, CHOP and $\mathrm{C} / \mathrm{EBP} \beta$ were located in the nuclei of the majority of cells (Figure 3a). Conversely, although little effect was observed for all these proteins in the non-tumorigenic MCF10A cells (Figure 2a), ATF4 protein levels were significantly increased (Figure 2e), mainly in the nuclei (Figure 3b), suggesting that this transcription factor can have an important role as a pro-survival factor in non-tumorigenic cells.

PDI immunostaining showed a striking dilation in the ER of ChoKIs-treated cancer cells, a hallmark of the ER stress response ${ }^{40}$ (Figure $3 \mathrm{c}$ ). PDI and CHOP proteins overproduction showed a similar effect that those observed in breast cancer cells (Supplementary Figure 4). 
a
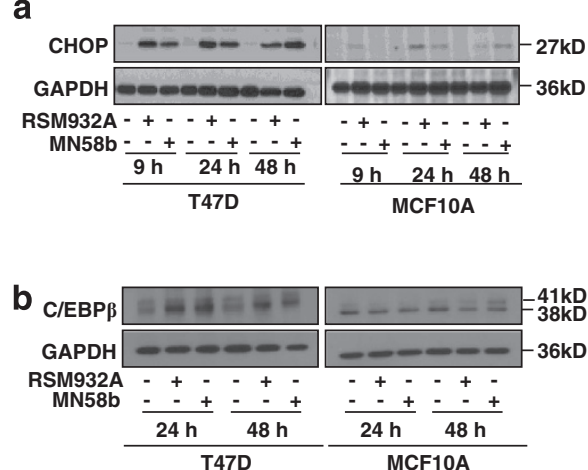

C
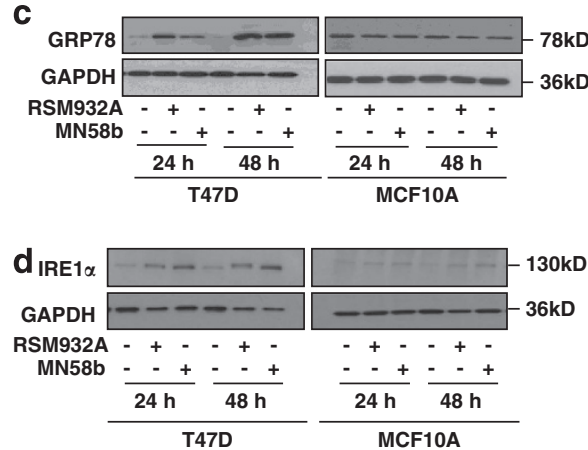

e
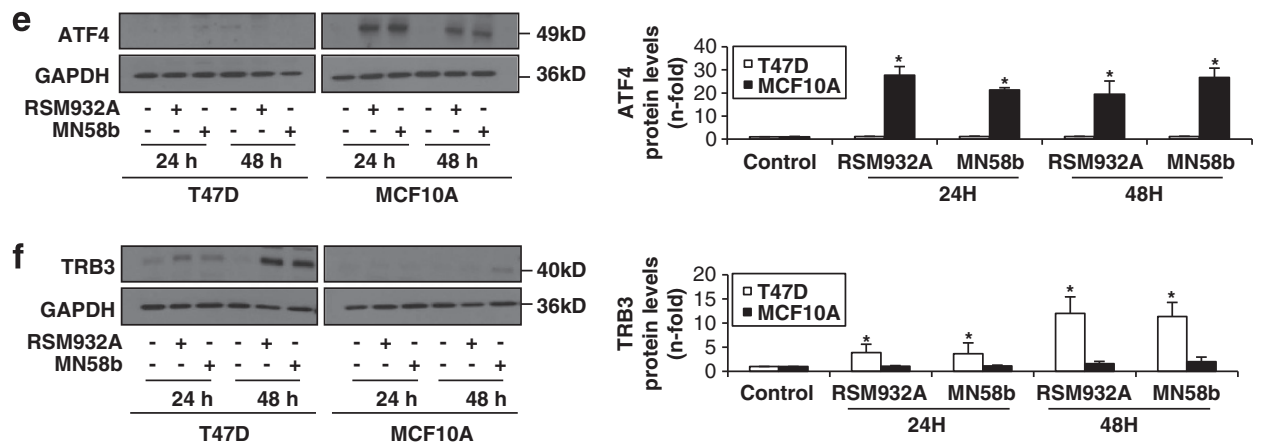

g
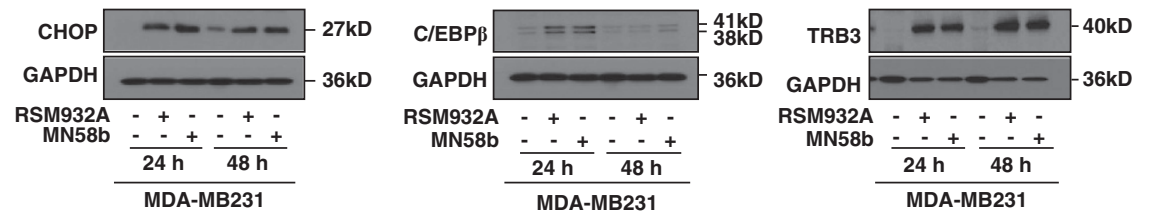

Figure 2 Choline kinase- $\alpha$ inhibitors markedly increase CHOP, C/EBP $\beta$, GRP78, IRE1 $\alpha$ and TRB3 protein levels in tumor cells and ATF4 protein production in nontumorogenic cells. Left panel shows representative western blots for CHOP (a), C/EBP $\beta$ (b), GRP78 (c), IRE1 $\alpha$ (d), ATF4 (e) and TRB3 (f) in T47D and MCF10A cell lines after treatment with ChoK $\alpha$ inhibitors. Right panel represents protein levels shown as mean \pm S.E.M. of four independent experiments. ${ }^{*} P<0.05$ versus control cells. (g) Shows representative immunoblots of three independent experiments for CHOP, C/EBP $\beta$ and TRB3 in MDA-MB231 cell line

CHOP overproduction induced by ChoKls is attenuated when $\mathrm{ChoK} \alpha$ protein levels are silenced. ChoK $\alpha$ siRNA assays were performed in order to confirm that the ER stress response induced by ChoKls is due to their specific interaction with ChoK $\alpha$. Although pharmacological inhibition of ChoK $\alpha$ induced a drastic alteration of CHOP, C/EBP $\beta$ and TRB3 (Figure 2), the partial ChoK $\alpha$ silencing achieved under these conditions failed to trigger ER stress in T47D (Figure 4a) and MDA-MB231 cells (Figure 4b). When cells were treated with RSM932A or MN58b for an additional $24 \mathrm{~h}$ after transfection with ChoK $\alpha$ siRNA for $48 \mathrm{~h}$, the lower the levels of ChoK $\alpha$, the more attenuated was the induction of CHOP by ChoKls (Figure 4c and Supplementary Figure 5A), indicating that ER stress response induced by ChoKls is triggered only in the presence of ChoK $\alpha$. To support this view, in vitro binding experiments of ChoK $\alpha$ with its inhibitor RSM932A showed that this interaction induces a conformational change that can be followed by its sensitivity to trypsin digestion that could trigger ER stress responses and CHOPdependent apoptosis (Supplementary Figure 5B). 


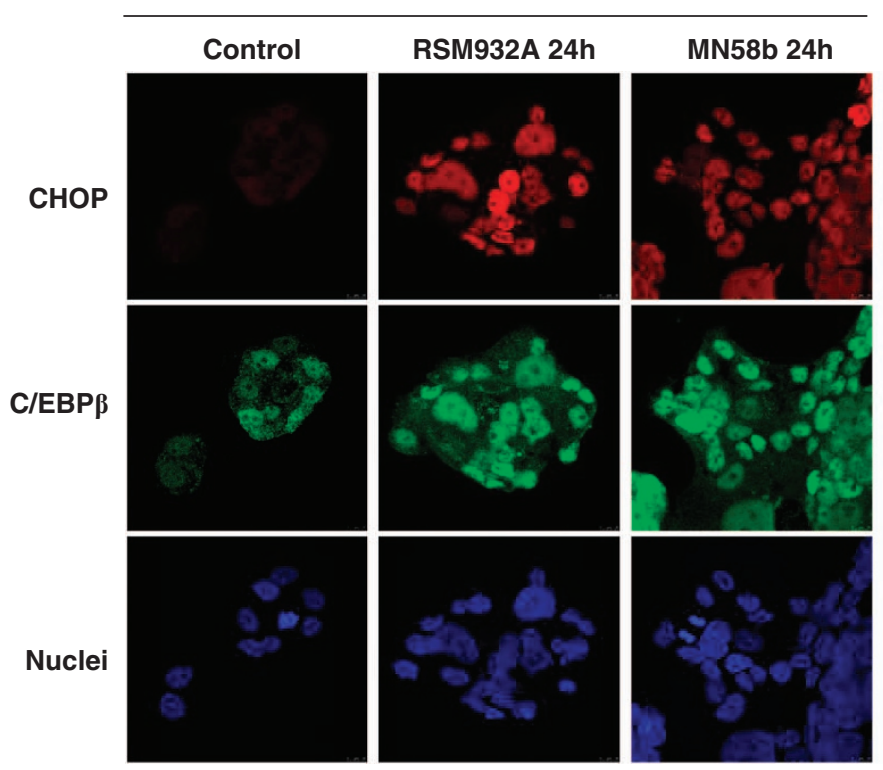

b

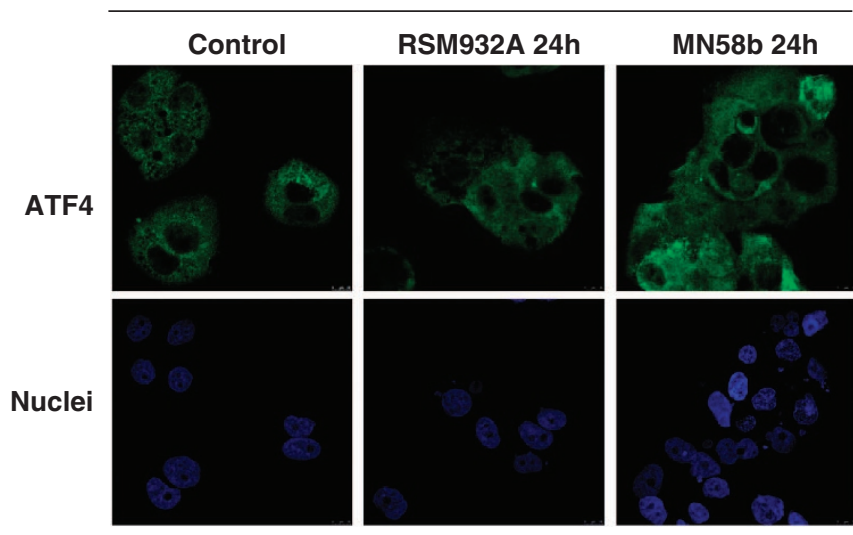

c

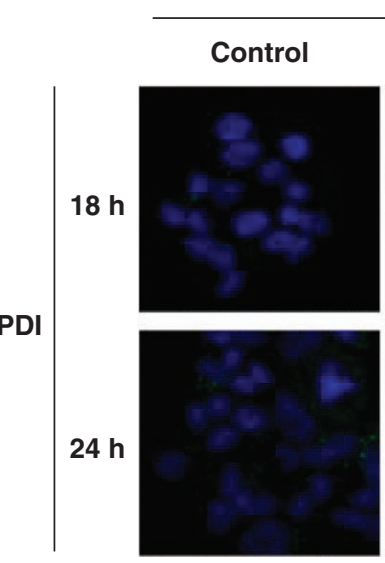

T47D
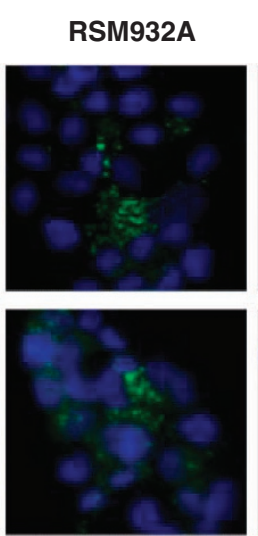

MCF10A

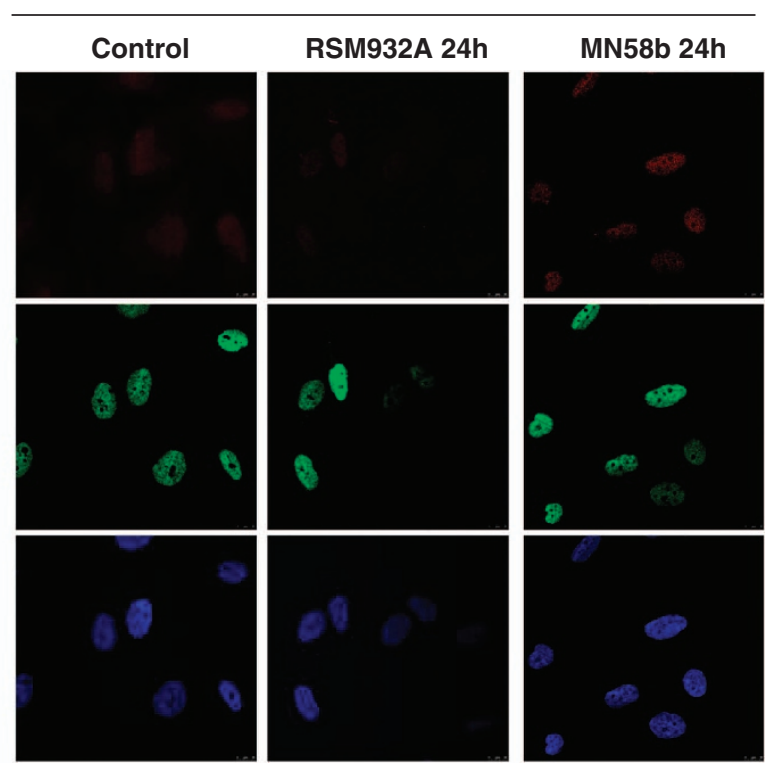

MCF10A

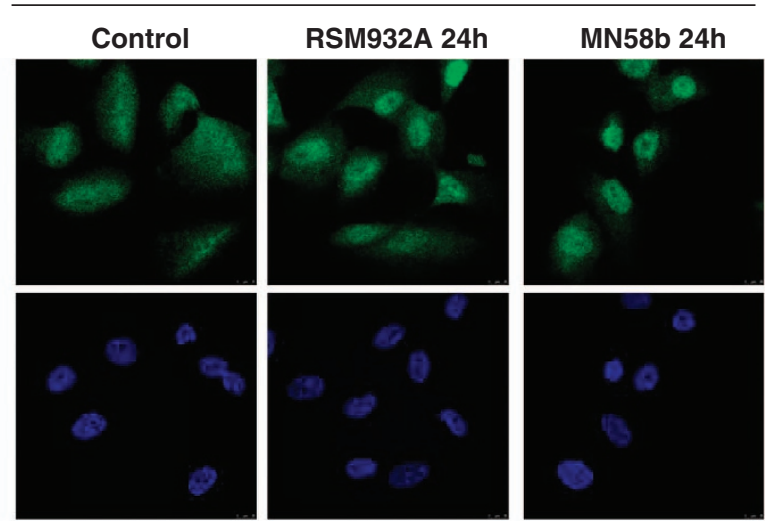

MCF10A

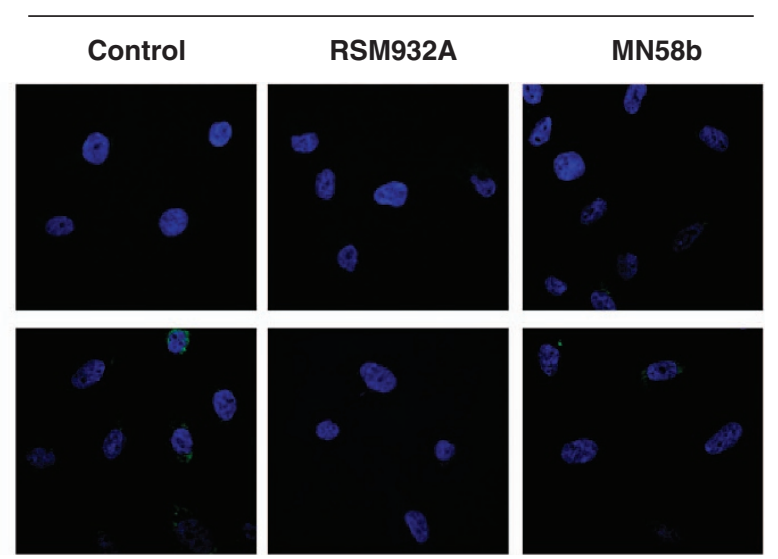

Figure 3 (a) $\mathrm{CHOP}$ and C/EBP $\beta$ show nuclear location in T47D and MCF10A tumor cells after treatment with ChoKIs. Figure shows representative images of CHOP and C/EBP $\beta$ staining of three independent experiments for each cell type. (b) ATF4 shows specific nuclear location in non-tumorogenic cells. Representative images, of three independent experiments, of ATF4 immunostaining. (c) ChoKIs induce PDI accumulation in tumor cells. The figure shows representative images of three independent experiments for each cell type, acquired with confocal microscopy for PDI immunostaining (green), after 18 and $24 \mathrm{~h}$ of ChoKls. Nuclei were stained with DAPI in all cases 

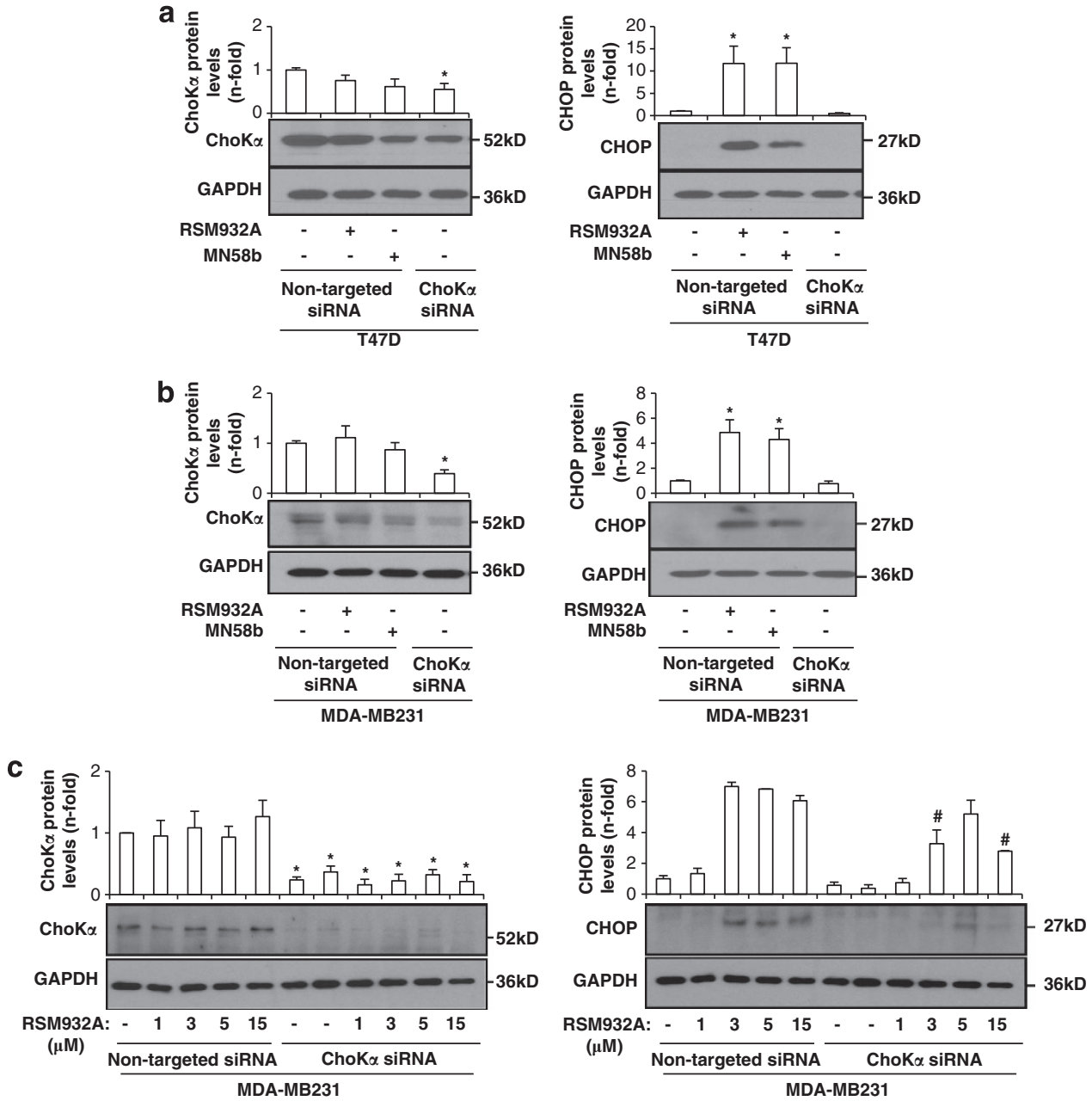

Figure 4 (a) ChoK $\alpha$ siRNA does not increase CHOP in T47D and MDA-MB231 cells. Cells were transiently transfected with ChoK $\alpha$ siRNA or a non-targeted siRNA for $24 \mathrm{~h}$. Afterwards, non-targeted siRNA-transfected cells were treated with ChoKls for $24 \mathrm{~h}$. Left panel shows protein levels of ChoK $\alpha$ in T47D (a) and MDA-MB231 (b). Right panel shows CHOP protein levels after ChoK $\alpha$ siRNA transfection. Data are shown as mean \pm S.E.M. of four independent experiments. ${ }^{*} P<0.05$ versus non-targeted siRNAtransfected control cells. (c) ChoK $\alpha$ silencing diminishes CHOP overproduction caused by RSM932A. Cells were transiently transfected with $30 \mathrm{nM}$ of ChoK $\alpha$ siRNA or a nontargeted siRNA for $48 \mathrm{~h}$, and then treated with RSM932A. Figure shows data as mean \pm S.E.M. of three independent experiments and a representative gel showing the levels of ChoK $\alpha$ or CHOP. GAPDH is shown as loading control. \#P<0.05 versus non-targeted siRNA + RSM932A-treated cells

CHOP mediates the cytotoxic effect of ChoKls in breast cancer cells. As treatment with ChoKIs induces high levels of $\mathrm{CHOP}$, we next assessed whether $\mathrm{CHOP}$ has a role in the cytotoxic effect of these inhibitors. CHOP siRNA was used to efficiently silence the protein in both MDA-MB231 and T47D cells (Figure $5 \mathrm{a}$ and Figure $5 \mathrm{~b}$, respectively). Flow cytometry analysis showed that ChoKls did not promote cell death in CHOP silenced cells compared with controls (Figure $5 \mathrm{c}$ ). Therefore, the induction of $\mathrm{CHOP}$ by ChoKls has a main role in the cytotoxic effect on tumor cells.

TRB3 has been described as a target gene of $\mathrm{CHOP}$ and as mediator of ER stress-induced apoptosis in several cell types. ${ }^{36,43}$ We next asked whether CHOP regulated the overproduction of TRB3 induced by ChoKIs. TRB3 levels were found unaltered independently of the CHOP levels (Figure 5d), suggesting that TRB3 overproduction is not regulated by $\mathrm{CHOP}$ after ChoKls treatment. The contribution of TRB3 to the cytotoxic effect caused by ChoKIs was also evaluated. TRB3 interference did not significantly modify the induction of cell death by either RSM932A or MN58b (Figure $5 \mathrm{e}$ ), and it is not directly involved in cell death induced by ChoKIs.

ATF4 has a survival role in non-tumorigenic cells. Although ChoKls induced ATF4 mRNA overexpression in tumor and non-tumorigenic cells, its protein level and nuclear location were only increased in the non-tumorigenic cells. We assessed whether this protein could participate in the cytostatic effect of ChoKIs in MCF10A. To that end, cells were transiently transfected with ATF4 siRNA and $24 \mathrm{~h}$ later treated with ChoKls for $24 \mathrm{~h}$ (Figure $6 \mathrm{a}$ ). Treatment with any of the ChoKls increased cell death in ATF4 silenced cells (Figures $6 \mathrm{~b}$ and $\mathrm{c}$ ). These results demonstrate a crucial role of ATF4 in survival and protection of non-tumorogenic cells treated with RSM932A or MN58b. 

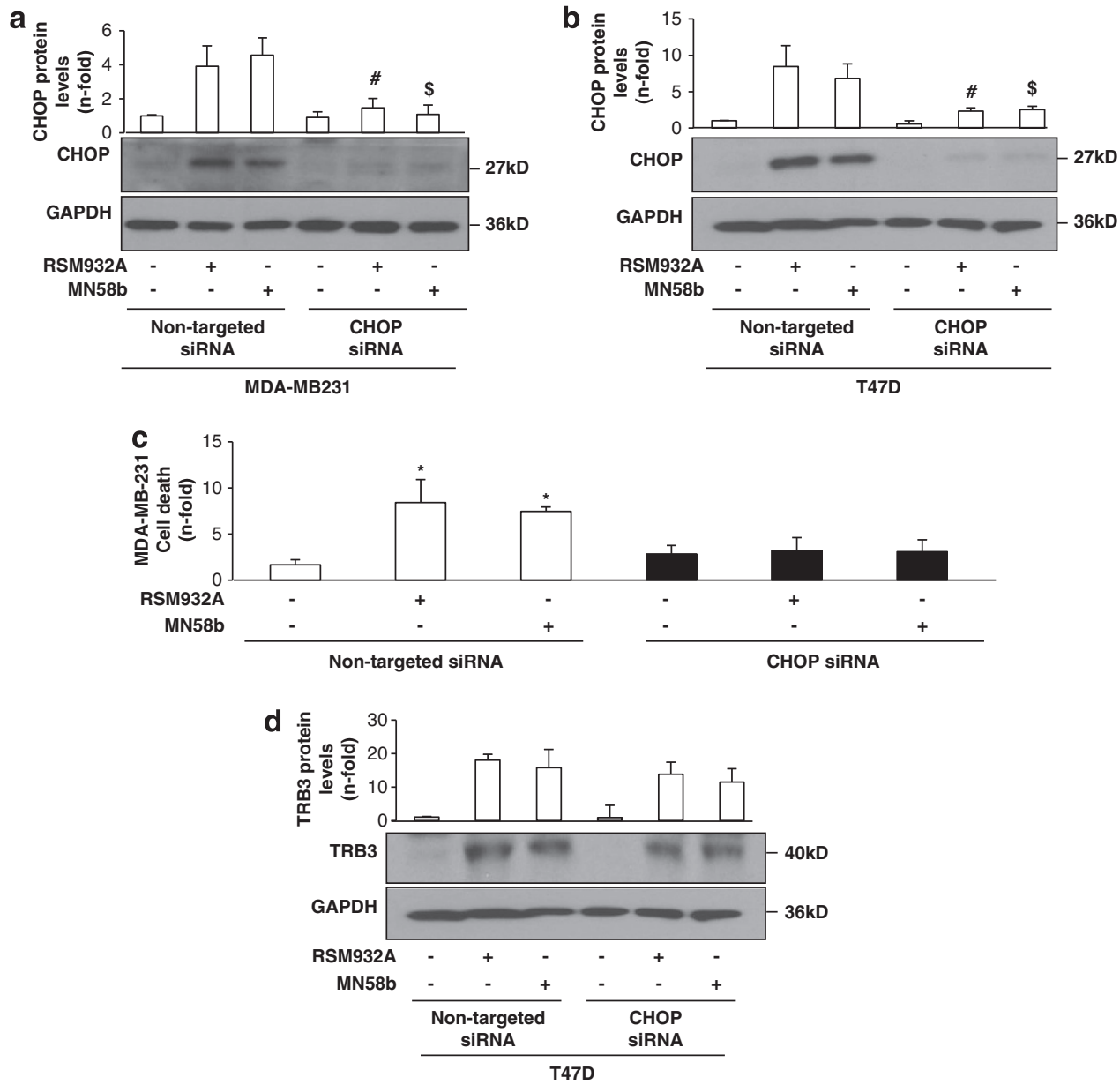

e
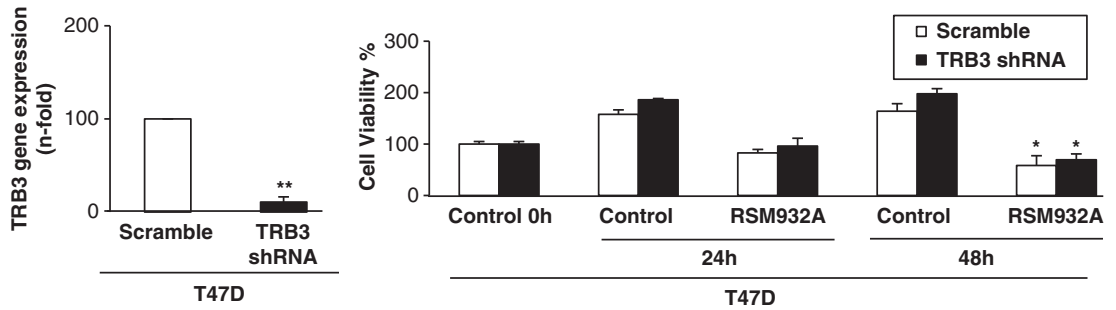

Figure 5 CHOP silenced tumor cells failed in the cytotoxic effect induced by ChoKIs. Cells were transiently transfected with $30 \mathrm{nM}$ of CHOP SMARTPOOL siRNA or a nontargeted siRNA for $24 \mathrm{~h}$. After that, cells were treated with ChoKIs for $24 \mathrm{~h}$. Panels (a and $\mathbf{b}$ ) show CHOP protein levels in MDA-MB231 and T47D, respectively. The graph bars show data as mean \pm S.E.M. of three independent experiments and representative immunoblots. $\# P<0.05$ versus non-targeted siRNA + RSM- $932 A$-treated cells. $\$ P<0.05$ versus non-targeted siRNA + MN58b-treated cells. (c) CHOP silenced tumor cells failed in apoptosis induced by ChoKls. The graph bars show cell death as mean \pm S.E.M. of three independent experiments. ${ }^{*} P<0.05$ versus non-targeted siRNA-transfected control cells. (d) TRB3 overexpression caused by ChoKls is not regulated by CHOP. Figure shows TRB3 protein levels in T47D transiently transfected with CHOP SMARTPOOL siRNA or a non-targeted siRNA for $24 \mathrm{~h}$ and then treated with ChoKls for $24 \mathrm{~h}$. Graph bars show data as mean \pm S.E.M. of three independent experiments and a representative gel. (e) TRB3 interference did not affect the cell death induction by ChoKIs in T47D tumor cells. TRB3 was downregulated by shRNA pLKO.1 lentiviral system. Figure shows on the left panel TRB3 gene expression as mean \pm S.E.M. of three independent experiments and on the right panel cellular viability percentage shown as mean \pm S.E.M. of three experiments each one performed by quadruplicated

\section{Discussion}

The relevance of ChoK $\alpha$ in tumor growth has been reported in some types of cancer where this enzyme was found to be overexpressed with high incidence. ${ }^{9,11}$ ChoK $\alpha$-specific inhibitors have been generated with proven antiproliferative activity in vitro and in vivo. ${ }^{20-23}$ The antitumor action of ChoKIs relies on the ability of these compounds to directly affect cellular viability through induction of apoptosis. In contrast, in nontumorigenic cells the blockage of de novo PCho synthesis by MN58b results in a reversible cell cycle arrest at G0/G1 phase. ${ }^{25}$ Here, we further confirm that MN58b and RSM932A exert cytotoxic effect in a variety of tumor cells and a cytostatic effect inducing G1 cell cycle arrest in non-tumorigenic mammary cells and normal derived colon mucosa primary cells. ChoKls induced a marked deficiency in $\mathrm{G} 1$ to $\mathrm{S}$ phases 
a

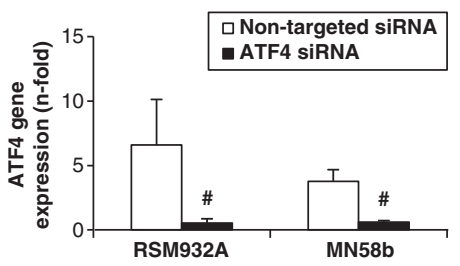

C
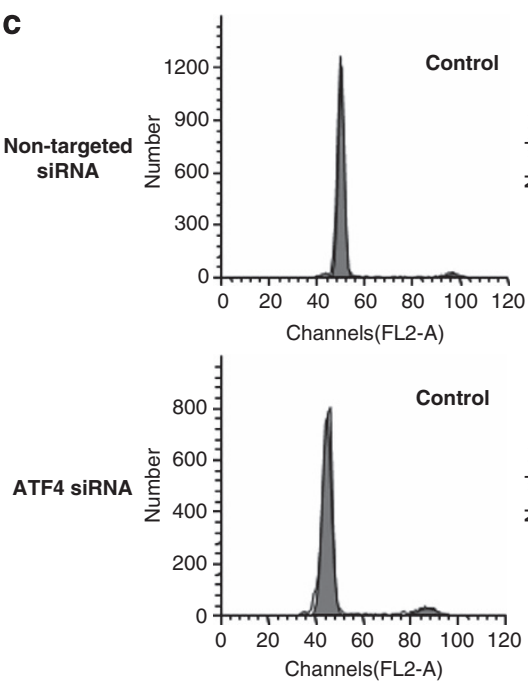

b
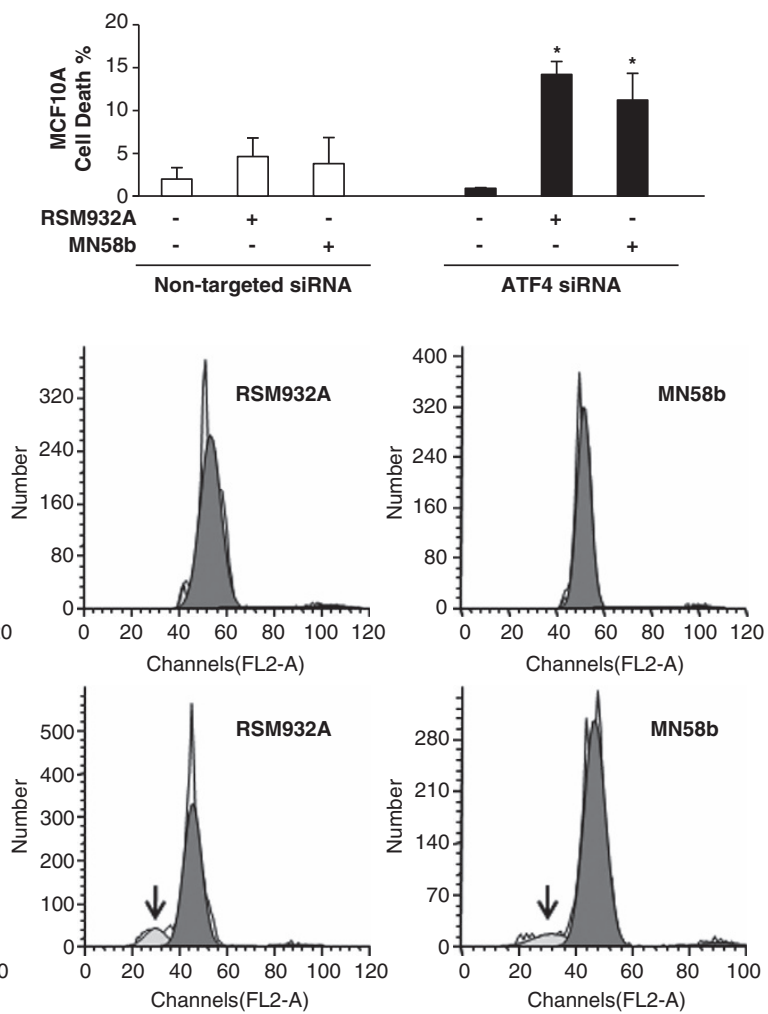

Figure 6 (a) ChoKls show cytotoxic effect on ATF4 silenced non-tumorogenic cells. Cells were transiently transfected with $30 \mathrm{nM}$ of ATF4 siRNA or a non-targeted siRNA for $24 \mathrm{~h}$. Afterward, cells were treated with ChoKIs for $24 \mathrm{~h}$. Figure (a) shows ATF4 mRNA gene expression as mean \pm S.D. of two independent experiments. Figure (b) exhibits cell death percentage as mean \pm S.D. of two experiments performed in duplicate and figure (c) shows representative histograms. ${ }^{*} P<0.05$ versus control. ${ }^{\sharp} P<0.05$ versus non-targeted siRNA-transfected cells

checkpoint mediators (cyclin D1, RB and E2F1 $\alpha$ ) in tumor cells, but in non-tumorigenic cells, the levels of E2F $1 \alpha$ and total RB are scarcely altered suggesting that arrest in G0/G1 may be due to maintenance of the RB-E2F $1 \alpha$ complex. Our data clearly indicate that RSM932A and MN58b have a differential cytostatic effect on non-tumorigenic cells and a cytotoxic effect on tumor cells, supporting further the use of ChoKIs as a novel and potent antitumor strategy with specific antiproliferative activity against different types of human tumor cells.

In human cancer cell lines, ChoK $\alpha$ inhibition promotes an exacerbated ER stress response, sustained by GRP78, $\mathrm{C} / \mathrm{EBP} \beta, \operatorname{IRE} 1 \alpha$ and TRB3 production, which leads to CHOPdependent apoptosis. Cell death mechanisms triggered by ER stress include both caspase-dependent apoptosis and caspase-independent necrosis. ${ }^{48}$ Moreover, only tumor cells showed pro-caspase 3 and PARP degradation, suggesting that these proteins are being ripped off as a consequence of ER stress activation of ChoKIs. Whether ChoKIs induce ER stress apoptosis mediated by necrosis should be further investigated.

The ER is an organelle that has essential roles in multiple cellular processes required for cell survival and normal cellular functions. Recent studies suggest an important role of ER stress in carcinogenesis, and alterations in ER homeostasis have been correlated with pathological states and particularly with cancer. Interfering with the activation of different arms of the UPR can inhibit tumor growth in vivo, arguing that it contributes to survival or growth of some cancer cells. ${ }^{49}$ The UPR is primarily an adaptive response to support cell survival by a selective induction of transcription, but if homeostasis cannot be re-established, the UPR triggers cell death. According to this, some antitumor agents, including vorinostat, sorafenib, tocotrienol, delta(9)-tetrahydrocannabinol, fenretinide and bortezomib lead to apoptosis induced by ER stress. ${ }^{33-36,38}$ The ability of the cells to handle this stress, and transcriptional and translational regulation of ER stress mediators, may therefore condition their intrinsic capacity to adapt for cell survival or, alternatively, to start the apoptotic program through ER-associated machineries. In this sense, ChoKls activate ER stress maintained response in tumor cells, but a slight ER proteins production was observed in nontumor cells, indicating a different ability in both tumor and nontumor cells to re-establish ER homeostasis disturbed by ChoKIs.

The results obtained after ChoKls treatment of nontumorigenic cells indicate that these cells are prone to ER stress adaptation through ATF4 overproduction and moderated increase of $\mathrm{CHOP}$ and $\mathrm{C} / \mathrm{EBP} \beta$. In fact, ATF4 nuclear location was only observed in non-tumorigenic cells, suggesting that only in these cells it is activating its target genes. In keeping with this, inhibition of ATF4 expression blocked 
proliferation and survival of non-tumorigenic cells. Moreover, HEK293 cells overexpressing ATF4 showed retarded growth in complete medium. ${ }^{50}$ We have observed increased cell death in non-tumorigenic cells silenced for ATF4 after treatment with ChoKIs, supporting its protective and prosurvival role.

Recent studies suggest that when a stress transcends from acute to persistent, the regulatory mechanisms based on UPR would promote sustained elevated levels of CHOP protein (despite of its short half-life), and the products of its target genes, triggering apoptotic pathways. ${ }^{51} \mathrm{CHOP}$ is ubiquitously expressed at very low levels, and markedly expressed by perturbations that induce stress in a wide variety of cells. ${ }^{41,52}$ Upon non-stressed conditions, CHOP remains in the cytosol, and stress leads to its accumulation in the nucleus. ${ }^{41}$ The overinduction of ER stress response observed after ChoKIs treatment is not cell type specific as ChoKls trigger this process in several types of breast, colon and lung cancer cells. CHOP protein levels were significantly increased at all times studied and accompanied by a significant increase of C/EBP $\beta$, GRP78, IRE1 $\alpha$, TRB3 and PDI, well-known markers for ER stress. In addition, ChoKIs also recruit $\mathrm{CHOP}$ and $\mathrm{C} / \mathrm{EBP} \beta$ in the nuclei at the same time, promoting its dependent transcriptional program in tumor cells. We show a sustained significant increase of $\mathrm{CHOP}$, mainly located in the nuclei. In addition, CHOP blockage using specific siRNA, abolished apoptosis induced by ChoKIs in tumor cells. CHOP silencing also induced a reduction on $\mathrm{C} / \mathrm{EBP} \beta, \mathrm{ATF} 3$ and GRP78 protein levels (data not shown), which in addition are also direct inducers of $\mathrm{CHOP}$. Cells lacking $\mathrm{C} / \mathrm{EBP} \beta$ (major partner of CHOP) are also resistant to ER stress-induced apoptosis. ${ }^{42}$ Thus, a specific, potent, overstated and persistent induction of ER proteins by ChoKIs drives the tumor cells to apoptosis mediated by elevated levels of CHOP.

TRB3 has been described as a novel ER stress-inducible gene that is a direct transcriptional target of ATF4 and CHOP and may have an important role in ATF4/CHOP-mediated apoptosis. ${ }^{43}$ Knockdown of ATF4 or CHOP significantly suppressed the induction of TRB3 in HEK293. ${ }^{50}$ Conversely, no change was observed in TRB3 levels in CHOP silenced cells treated with RSM932A or MN58b, indicating that in this case TRB3 is not directly involved in the cytotoxic effect of high levels of CHOP. The implication of TRB3 in the mechanism of action of ChoKls has to be more deeply investigated.

$\mathrm{PC}$ depletion can disturb the ER function and result in ER stress. $^{32,53}$ Inhibition of PC synthesis through mutated CTP:phosphocholine cytidylyltransferase enzyme leads specifically to induction of the ER stress-related protein CHOP and apoptosis. ${ }^{32}$ Moreover, the C/EBP-ATF composite sites are required for the increased expression of $\mathrm{CHOP}$ during $\mathrm{PC}$ depletion and might be mediated by binding of ATF2 to this element. ${ }^{53}$ The specific effect of ChoKls is not observed after siRNA ChoK $\alpha$ inhibition. Specific pharmacological inhibition and ChoK $\alpha$ siRNA efficiently reduced ChoK $\alpha$ activity and PCho levels, ${ }^{15-18}$ but ChoK $\alpha$ siRNA failed in the activation of ER stress response. The different strategies to block ChoK $\alpha$ by siRNA or specific pharmacological inhibition might explain this differential effect. Our results indicate that ER stress response triggered by ChoKls depends on the presence of $\mathrm{ChoK} \alpha$, as the higher the silencing of $\mathrm{ChoK} \alpha$ protein, the lesser the induction of CHOP was observed after ChoKIs treatment. In vitro binding experiments suggest that ChoK $\alpha$ conformation might be modified after ChoKls interaction, increasing the potential of apoptosis induction of this family of inhibitors by combining a metabolic effect by depleting PC synthesis, and a UPR response. These results are consistent with a dual effect of ChoKIs and are in keeping with recent reports demonstrating a complex interaction of ChoK $\alpha$ with its inhibitors. ${ }^{54,55}$

Accumulation of proteins with wrong conformations or unfolded proteins in the ER results in the induction of several proteins, including the ER chaperones GRP78 and GRP94, which facilitates proper protein folding by interacting with exposed hydrophobic patches on protein-folding intermediates and is thought to prevent their aggregation while maintaining the protein in a folding-competent state. ${ }^{32,56}$ Furthermore, ER stress can activate transmembrane proteins located in the ER membrane like IRE $1 \alpha$ and PERK, which inhibit general protein synthesis and activate the noncanonical apoptosis response. ChoKIs dramatically increase GRP78, IRE $1 \alpha$ and CHOP, which suggests that the exacerbated induction of ER stress response depends on ChoK $\alpha$ protein presence in the cells, and the levels of ChoK $\alpha$ are crucial for the ER stress-mediated apoptosis by these inhibitors. Furthermore, non-cytotoxic doses of both MN58b and RSM932A showed a significant increase of CHOP in a dose-dependent manner (data not shown), which dismisses that it is an off-target effect and support that ER stress induction caused by ChoKls may be directly related to the inhibition of ChoK $\alpha$ activity.

In summary, ChoK $\alpha$ inhibition leads to exacerbated ER stress response and $\mathrm{CHOP}$ overproduction that has a crucial role in the cytotoxic effect of ChoKIs in tumor cells. In addition, ATF4 might represent a pathway for cell survival in nontumorigenic cells. Our data provide relevant evidence for a rational understanding of the selective and specific apoptotic effect on tumor cells, and support further preclinical and clinical studies with this novel family of anticancer drugs.

\section{Materials and Methods}

Cell culture and reagents. Cell lines were grown under standard conditions: T47D (epithelial mammary cells from ductal carcinoma), MCF7 (epithelial mammary gland cells from adenocarcinoma), $\mathrm{H} 460$ (epithelial large cell non-small-cell lung cancer); were cultured in RPMI (Invitrogen, Casbard, CA, USA); MDA-MB231 (epithelial mammary gland cells from adenocarcinoma) and SW620 (colorectal adenocarcinoma), cultured in DMEM (Invitrogen), supplemented all of them with $10 \%$ fetal bovine serum (Invitrogen). MCF10A (non-tumorigenic epithelial gland mammary cell line) were grown in DMEM-F12 (Invitrogen) supplemented with 10\% newborn calf serum (Biochrom, Berlin, Germany), $10 \mu \mathrm{g} / \mathrm{ml}$ Epidermal growth factor (Calbiochem, Merck, Darmstadt, Germany), $50 \mu \mathrm{g} / \mathrm{ml}$ hydrocortisone, $2.5 \mathrm{mg} / \mathrm{ml}$ insulin and $100 \mathrm{ng} / \mathrm{ml}$ cholera toxin (from Sigma-Aldrich, St. Louis, MO, USA). NCM460 cells (normal derived colon mucosa cells) were received by a licensing agreement with INCELL Corporation (San Antonio, TX, USA). They were routinely propagated on M3BASE medium plus supplements and $10 \%$ FBS. All experiments were performed at $50 \%$ of confluence.

First- and second-generation inhibitors of ChoK $\alpha$ were used. MN58b was dissolved in water at $5 \mathrm{mmol}$, and RSM932A was dissolved in DMSO : Water $(2: 1)$ at $5 \mathrm{mmol}$. The vehicle DMSO: Water $(2: 1)$ were used as Control. Both drugs are produced at Prof. Lacal's laboratory and are not available as commercial compounds.

Flow cytometry analysis. Cells were seeded at a density of $20 \times 10^{4}$ cells/ well on six-well plates and treated $24 \mathrm{~h}$ later with MN58b and RSM932A. 
Supernatants and cultured cells were collected and centrifuged at 1800 r.p.m. for $15 \mathrm{~min}$. Then cells were diluted in $1 \times \mathrm{PBS}$ with PI $(50 \mu \mathrm{g} / \mathrm{ml})$, RNAse A $(20 \mu \mathrm{g} / \mathrm{ml})$ and TX-100 $(50 \mu l)$. The DNA content of stained cells was analyzed using a FACScan flow cytometer (Becton Dickinson and Company, Franklin Lakes, NJ, USA) and Cell Quest Pro software (Becton Dickinson and Company). The fraction of cells in apoptosis (sub-G1), G0-G1, S and G2-M phases were quantified by MODFIT LT 3.0 software (Verity Software House, Topsham, ME, USA).

Cell viability assays (MTT). Cells were seeded at a density of $5 \times 10^{3}$ cells/well on 96-well plates. Then, cells were treated with MN58b or RSM932A during 24 and $48 \mathrm{~h}$. Cellular viability was studied by 3-(4,5-dimethylthiazol-2yl)-2, 5-diphenyl tetrazoliumbromide (MTT) method (Invitrogen). Absorbance was read at $560 \mathrm{~nm}$ in a VersaMax Microplate Reader (Molecular Devices, Sunnyvale, CA, USA).

Protein analysis. Equal amounts of lysed proteins were separated by SDS-PAGE electrophoresis, transferred onto nitrocellulose membranes using iBlot Dry Blotting System (Invitrogen) and immunoblotted with pro-caspase 3; cyclin D1, phospho-RB, RB (Santa Cruz Biotechnology, Heidelberg, Germany); CHOP, GRP78 and IRE $1 \alpha$ (Cell Signaling, Danvers, MA, USA); C/EBP $\beta$, TRB3, ATF4, ATF3 (AbCam, Cambridge, UK) and ChoK $\alpha$ antibody. $\alpha$-Actin (Sigma-Aldrich) and GAPDH (Millipore, Billerica, MA, USA) were used as loading controls. Membranes were incubated with peroxidase-conjugated secondary antibody (Santa Cruz Biotechnology) and developed using an ECL chemiluminiscence kit (Amersham Pharmacia Biotech, Piscataway, NJ, USA). Autoradiographs were scanned and Quantity One software was used for densitometric analyses (Bio-Rad, Madrid, Spain).

Gene expression studies. Total mRNA was isolated using RNeasy mini Kit (Qiagen, Hilden, Germany). cDNA was synthesized using High Capacity cDNA Archive Kit (Applied Biosystems, Life Technologies, Carlsbad, CA, USA) using $1 \mu \mathrm{g}$ of total RNA primed with random hexamer primers following the manufacturer's instructions. Real-time RT-PCR was performed using fluorogenic TaqMan gene expression assays (Applied Biosystems): CHOP (Hs_01090850_m1), C/EBP $\beta$ (Hs_00270923_s1), ATF4 (Hs_00909569_g1) and TRB3 (Hs_00221754_m1). Data were normalized with 18S eukaryotic ribosomal RNA expression (Hs99999901_m1). The mRNA copy numbers were calculated for each sample by the instrument software using $\mathrm{Ct}$ value ('arithmetic fit point analysis for the lightcycler'). Results are expressed as the quantity of the target gene after treatment relative to unstimulated cells, after normalization against $18 \mathrm{~S}$.

siRNA and shRNA transfection studies. Cells were transfected using Lipofectamine 2000 reagent (Invitrogen) and $30 \mathrm{nM}$ siRNA for ATF4 (Eurogentec S.A., Liege, Belgium), CHOP on-target plus SMARTpool CHOP (Dharmacon Inc., Chicago, IL, USA), ChoK $\alpha$ (Qiagen) and non-targeted siRNA as control (Ambion, Life Technologies, Carlsbad, CA, USA) as described by the manufacturer's instructions. Lentiviruses were generated by co-transfecting Hek293T cells with $10 \mu \mathrm{g}$ of TRB3 shRNA-encoding plasmid (Dharmacon Inc.) and $8.75 \mu \mathrm{g}$ each of pDelta 8.9 (ps_PAX29 and VSV-60 (pMD2.G) plasmids using Lipofectamine 2000 (Invitrogen). Growth media were exchanged the following day and lentiviruscontaining supernatant was harvested $48 \mathrm{~h}$ later. Target cell lines were transduced with lentiviral RNAi at $\mathrm{MOI}=1$ and selected in $1 \mu \mathrm{g} / \mathrm{ml}$ puromycin for 1 week.

Native gel analysis. Ten micromolar samples of Plasmodium falciparum and human choline kinase were incubated with DMSO or $100 \mu \mathrm{M}$ of RSM932A in Kinase Buffer (100 mM Tris, pH 8, $10 \mathrm{mM} \mathrm{MgCl}$ ) for $1.5 \mathrm{~h}$ on ice and after the addition of an appropriate loading buffer were loaded onto a 4-20\% Mini-Protean TGX native gel (Bio-Rad).

Trypsin degradation. Ten micromolar samples of $P$. falciparum and human choline kinase were incubated with either DMSO or $100 \mu \mathrm{M}$ of RSM932A in Kinase Buffer in the presence of $3 \mu \mathrm{g} / \mathrm{ml}$ of trypsin at 37 degrees for $1 \mathrm{~h}$. Samples aliquots were removed at 5, 10, 20,30 and $60 \mathrm{~min}$, and placed on ice. Sample buffer was immediately added and trypsin degradation reaction was stopped by incubating for $5 \mathrm{~min}$ at 95 degrees. Samples were then loaded onto a $12 \%$ SDS-PAGE gel. Coomasie-stained bands representing undegraded choline kinase were quantified using the Quantity One software and normalized against a band representing a sample lacking trypsin.

Immunofluorescence staining. To assess $\mathrm{CHOP}, \mathrm{C} / \mathrm{EBP} \beta$, ATF4 and PDI staining, cells were fixed with $4 \%$ PFA. After permeabilizing with $0.3 \%$
TX-100, samples were blocked with $4 \%$ BSA and incubated with primary antibodies: PDI, CHOP (Cell Signaling), C/EBP $\beta$ and ATF4 (Santa Cruz Biotechnology). After washing, cells were incubated with Alexa secondary antibodies (Invitrogen), and nuclei were stained with DAPI (Invitrogen). Negative control was performed in the absence of primary antibody or using non-related secondary antibodies. Samples were mounted with ProLong gold (Invitrogen) and examined using TSC SP2 confocal microscope (Leica, Barcelona, Spain).

Statistical analysis. One-way ANOVA was used to compare gene and/or protein expression levels between groups. When statistical significance was found, the Bonferroni post hoc comparison test was used to identify differences between groups. Differences were considered significant at $P<0.05$. Statistical analyses were performed using the SPSS statistical software, version 11.0.

\section{Conflict of Interest}

The authors declare no conflict of interest.

Acknowledgements. This work has been funded by the following grants: Comunidad de Madrid (S2010/BMD-2326), Ministerio de Economía y Competitividad (SAF2011-29699, RD06-0020-0016 and RD12/0036/0019) and EU no. 259737. ESL is a Sara Borell fellow under the program ISCIII/MICINN.

1. Cui Z, Houweling M. Phosphatidylcholine and cell death. Biochim Biophys Acta 2002; 1585: 87-96.

2. Ramirez de Molina A, Penalva V, Lucas L, Lacal JC. Regulation of choline kinase activity by Ras proteins involves Ral-GDS and PI3K. Oncogene 2002; 21: 937-946.

3. Ramirez de Molina A, Rodriguez-Gonzalez A, Penalva V, Lucas L, Lacal JC. Inhibition of ChoK is an efficient antitumor strategy for Harvey-, Kirsten-, and N-ras-transformed cells. Biochem Biophys Res Commun 2001; 285: 873-879.

4. Ratnam S, Kent $\mathrm{C}$. Early increase in choline kinase activity upon induction of the H-ras oncogene in mouse fibroblast cell lines. Arch Biochem Biophys 1995; 323: 313-322.

5. Teegarden D, Taparowsky EJ, Kent C. Altered phosphatidylcholine metabolism in C3H10T1/2 cells transfected with the Harvey-ras oncogene. J Biol Chem 1990; 265: $6042-6047$.

6. de Certaines JD, Larsen VA, Podo F, Carpinelli G, Briot O, Henriksen O. In vivo 31P MRS of experimental tumours. NMR Biomed 1993; 6: 345-365.

7. Ruiz-Cabello J, Cohen JS. Phospholipid metabolites as indicators of cancer cell function. NMR Biomed 1992; 5: 226-233.

8. Smith TA, Bush C, Jameson C, Titley JC, Leach MO, Wilman DE et al. Phospholipid metabolites, prognosis and proliferation in human breast carcinoma. NMR Biomed 1996; 6 : 318-323.

9. Ramirez de Molina A, Rodriguez-Gonzalez A, Gutierrez R, Martinez-Pineiro L, Sanchez J, Bonilla $F$ et al. Overexpression of choline kinase is a frequent feature in human tumorderived cell lines and in lung, prostate, and colorectal human cancers. Biochem Biophys Res Commun 2002; 296: 580-583.

10. Li M, Peng Z, Liu Q, Sun J, Yao S, Liu Q. Value of 11 -choline PET/CT for lung cancer diagnosis and the relation between choline metabolism and proliferation of cancer cells. Oncol Rep 2013; 29: 205-211.

11. Ramirez de Molina A, Gutierrez R, Ramos MA, Silva JM, Silva J, Bonilla F et al. Increased choline kinase activity in human breast carcinomas: clinical evidence for a potential novel antitumor strategy. Oncogene 2002; 21: 4317-4322.

12. Ramirez de Molina A, Banez-Coronel M, Gutierrez R, Rodriguez-Gonzalez A, Olmeda D, Megias $\mathrm{D}$ et al. Choline kinase activation is a critical requirement for the proliferation of primary human mammary epithelial cells and breast tumor progression. Cancer Res 2004; 64: $6732-6739$.

13. Ramirez de Molina A, Sarmentero-Estrada J, Belda-Iniesta C, Taron M, Ramirez de Molina V, Cejas $\mathrm{P}$ et al. Expression of choline kinase alpha to predict outcome in patients with early-stage non-small-cell lung cancer: a retrospective study. Lancet Oncol 2007; 8: 889-897.

14. Kwee SA, Hernandez B, Chan O, Wong L. Choline kinase alpha and hexokinase-2 protein expression in hepatocellular carcinoma: association with survival. PLOS One 2012; 7: e46591.

15. Glunde K, Raman V, Mori N, Bhujwalla ZM. RNA interference-mediated choline kinase suppression in breast cancer cells induces differentiation and reduces proliferation. Cancer Res 2005; 65: 11034-11043.

16. Al-Saffar NM, Troy H, Ramirez de Molina A, Jackson LE, Madhu B, Griffiths JR et al. Noninvasive magnetic resonance spectroscopic pharmacodynamic markers of the choline kinase inhibitor MN58b in human carcinoma models. Cancer Res 2006; 66: 427-434.

17. Mori N, Glunde K, Takagi T, Raman V, Bhujwalla ZM. Choline kinase down-regulation increases the effect of 5-fluorouracil in breast cancer cells. Cancer Res 2007; 67: $11284-11290$. 
18. Clem BF, Clem AL, Yalcin A, Goswami U, Arumugam S, Telang $S$ et al. A novel small molecule antagonist of choline kinase-alpha that simultaneously. Oncogene 2011; 30 3370-3380.

19. Banez-Coronel M, Ramirez de Molina A, Rodriguez-Gonzalez A, Sarmentero J, Ramos MA, Garcia-Cabezas MA et al. Choline kinase alpha depletion selectively kills tumoral cells. Curr Cancer Drug Targets 2008; 8: 709-719.

20. Hernandez-Alcoceba R, Fernandez F, Lacal JC. In vivo antitumor activity of choline kinase inhibitors: a novel target for anticancer drug discovery. Cancer Res 1999; 59: 3112-3118.

21. Hernandez-Alcoceba R, Saniger L, Campos J, Nunez MC, Khaless F, Gallo MA et al Choline kinase inhibitors as a novel approach for antiproliferative drug design. Oncogene 1997; 15: 2289-2301.

22. Rodriguez-Gonzalez A, Ramirez de Molina A, Fernandez F, Ramos MA, del Carmen Nunez M, Campos J et al. Inhibition of choline kinase as a specific cytotoxic strategy in oncogene-transformed cells. Oncogene 2003; 22: 8803-8812.

23. Rodriguez-Gonzalez A, Ramirez de Molina A, Fernandez F, Lacal JC. Choline kinase inhibition induces the increase in ceramides resulting in a highly specific and selective cytotoxic antitumoral strategy as a potential mechanism of action. Oncogene 2004; 23: 8247-8259.

24. Gómez-Pérez V, McSorley T, See Too WC, Konrad M, Campos JM. Novel 4-amino bis-pyridinium and bis-quinolinium derivatives as choline kinase inhibitors with antiproliferative activity against the human breast cancer SKBR-3 cell line. ChemMedChem 2012; 7: 663-669.

25. Rodriguez-Gonzalez A, Ramirez de Molina A, Banez-Coronel M, Megias D, Lacal JC. Inhibition of choline kinase renders a highly selective cytotoxic effect in tumour cells through a mitochondrial independent mechanism. Int J Oncol 2005; 26: 999-1008.

26. Palacios Izquierdo $B$, van Hoogevest $P$. Inventors, TCD Pharma assignee. Pharmaceutical compositions of pyridinium and quinolinium derivatives; PCT/EP2011/073722.

27. Hung JY, Hsu YL, Ni WC, Tsai YM, Yang CJ, Kuo PL et al. Oxidative and endoplasmic reticulum stress signaling are involved in dehydrocostuslactone-mediated apoptosis in human non-small cell lung cancer cells. Lung Cancer 2010; 68: 355-365.

28. Abcouwer SF, Marjon PL, Loper RK, Vander Jagt DL. Response of VEGF expression to amino acid deprivation and inducers of endoplasmic reticulum stress. Invest Ophthalmo Vis Sci 2002; 43: 2791-2798.

29. Soboloff J, Berger SA. Sustained ER Ca2 + depletion suppresses protein synthesis and induces activation-enhanced cell death in mast cells. J Biol Chem 2002; 277: 13812-13820.

30. Yung HW, Korolchuk S, Tolkovsky AM, Charnock-Jones DS, Burton GJ. Endoplasmic reticulum stress exacerbates ischemia-reperfusion-induced apoptosis through attenuation of Akt protein synthesis in human choriocarcinoma cells. FASEB J. 2007; 21: 872-884.

31. Feldman DE, Chauhan V, Koong AC. The unfolded protein response: a novel component of the hypoxic stress response in tumors. Mol Cancer Res 2005; 3: 597-605.

32. van der Sanden $M H$, Houweling M, van Golde LM, Vaandrager AB. Inhibition of phosphatidylcholine synthesis induces expression of the endoplasmic reticulum stress and apoptosis-related protein CCAAT/enhancer-binding protein-homologous protein (CHOP/ GADD153). Biochem J. 2003; 369: 643-650.

33. Park SK, Sanders BG, Kline K. Tocotrienols induce apoptosis in breast cancer cell lines via an endoplasmic reticulum stress-dependent increase in extrinsic death receptor signaling Breast Cancer Res Treat 2010; 124: 361-375.

34. King FW, Fong S, Griffin C, Shoemaker M, Staub R, Zhang YL et al. Timosaponin Alll is preferentially cytotoxic to tumor cells through inhibition of mTOR and induction of ER stress. PLoS One 2009; 4: e7283.

35. Wali VB, Bachawal SV, Sylvester PW. Endoplasmic reticulum stress mediates gammatocotrienol-induced apoptosis in mammary tumor cells. Apoptosis 2009; 14: 1366-1377.

36. Carracedo A, Lorente M, Egia A, Blazquez C, Garcia S, Giroux V et al. The stressregulated protein p8 mediates cannabinoid-induced apoptosis of tumor cells. Cancer Cell 2006; 9: 301-312.

37. Armstrong JL, Flockhart R, Veal GJ, Lovat PE, Redfern CP. Regulation of endoplasmic reticulum stress-induced cell death by ATF4 in neuroectodermal tumor cells. J Biol Chem 2010; 285: 6091-6100
38. Park MA, Zhang G, Martin AP, Hamed H, Mitchell C, Hylemon PB et al. Vorinostat and sorafenib increase ER stress, autophagy and apoptosis via ceramide-dependent CD95 and PERK activation. Cancer Biol Ther 2008; 7: 1648-1662.

39. Moenner M, Pluquet $\mathrm{O}$, Bouchecareilh $\mathrm{M}$, Chevet $\mathrm{E}$. Integrated endoplasmic reticulum stress responses in cancer. Cancer Res 2007; 67: 10631-10634.

40. Schröder M, Kaufman RJ. The mammalian unfolded protein response. Annu Rev Biochem 2005; 74: 739-789.

41. Oyadomari S, Mori M. Roles of CHOP/GADD153 in endoplasmic reticulum stress. Cell Death Differ 2004; 11: 381-389.

42. Zinszner H, Kuroda M, Wang X, Batchvarova N, Lightfoot RT, Remotti $\mathrm{H}$ et al. CHOP is implicated in programmed cell death in response to impaired function of the endoplasmic reticulum. Genes Dev 1998; 12: 982-995.

43. Ohoka N, Yoshii S, Hattori T, Onozaki K, Hayashi H. TRB3, a novel ER stress-inducible gene, is induced via ATF4-CHOP pathway and is involved in cell death. EMBO J. 2005; 24: 1243-1255

44. Harding HP, Zhang Y, Zeng H, Novoa I, Lu PD, Calfon M et al. An integrated stress response regulates amino acid metabolism and resistance to oxidative stress. Mol Cell 2003: 11: 619-633.

45. Ye J, Kumanova M, Hart LS, Sloane K, Zhang H, De Panis DN et al. The GCN2-ATF4 pathway is critical for tumour cell survival and proliferation in response to nutrient deprivation. EMBO J. 2003; 29: 2082-2096.

46. Rzymski T, Milani M, Singleton DC, Harris AL. Role of ATF4 in regulation of autophagy and resistance to drugs and hypoxia. Cell Cycle 2009; 8: 3838-3847.

47. Moyer MP, Manzano LA, Merriman RL, Stauffer JS, Tanzer LR. NCM460, a normal human colon mucosal epithelial cell line. In Vitro Cell Dev Biol Anim 1996; 32 : 315-317.

48. Egger L, Schneider J, Rheme C, Tapernoux M, Hacki J, Borner C. Serine proteases mediate apoptosis-like cell death and phagocytosis under caspase-inhibiting conditions. Cell Death Differ 2003; 10: 1188-1203.

49. Lee AS, Hendershot LM. ER stress and cancer. Cancer Biol Ther 2006; 5: 721-722.

50. Ord D, Meerits $\mathrm{K}$, Ord T. TRB3 protects cells against the growth inhibitory and cytotoxic effect of ATF4. Exp Cell Res 2007; 313: 3556-3567.

51. Palam LR, Baird TD, Wek RC. Phosphorylation of elF2 facilitates ribosomal bypass of an inhibitory upstream ORF to enhance CHOP translation. J Biol Chem 2011; 286. 10939-10949

52. Maytin EV, Ubeda M, Lin JC, Habener JF. Stress-inducible transcription facto $\mathrm{CHOP} / g a d d 153$ induces apoptosis in mammalian cells via p38 kinase-dependent and independent mechanisms. Exp Cell Res 2001; 267: 193-204.

53. van der Sanden $\mathrm{MH}$, Meems $\mathrm{H}$, Houweling $\mathrm{M}$, Helms JB, Vaandrager $\mathrm{AB}$. Induction of CCAAT/enhancer-binding protein (C/EBP)-homologous protein/growth arrest and DNA damage-inducible protein 153 expression during inhibition of phosphatidylcholine synthesis is mediated via activation of a $\mathrm{C} / \mathrm{EBP}$-activating transcription factor-responsive element. J Biol Chem 2004; 279: 52007-52015.

54. Sahún-Roncero M, Rubio-Ruiz B, Saladino G, Conejo-García A, Espinosa A, Velázquez-Campoy $A$ et al. The mechanism of allosteric coupling in choline kinase $\alpha 1$ revealed by the action of a rationally designed inhibitor. Angew Chem Int Ed Engl 2013; 52 : 4582-4586.

55. Hudson CS, Knegtel RM, Brown K, Charlton PA. Kinetic and mechanistic characterisation of choline kinase- $\alpha$. Biochim Biophys Acta 2013; 1834: 1107-1116.

56. Ocker M, Höpfner M. Apoptosis-modulating drugs for improved cancer therapy. Eur Surg Res 2012; 48: 111-120.

(c) (1) $\odot$ Cell Death and Disease is an open-access journal published by Nature Publishing Group. This work is licensed under a Creative Commons Attribution-NonCommercialNoDerivs 3.0 Unported License. To view a copy of this license, visit http://creativecommons.org/licenses/by-nc-nd/3.0/

Supplementary Information accompanies this paper on Cell Death and Disease website (http://www.nature.com/cddis) 